\title{
Understanding the geographical development of social movements: a web-link analysis of Slow Food
}

\author{
BAS HENDRIKX, ${ }^{*}$ STEFAN DORMANS, ${ }^{\dagger}$ \\ ARNOUD LAGENDIJK ${ }^{\ddagger}$ AND MIKE THELWALL ${ }^{\S}$ \\ *(corresponding author) Geography, Planning and Environment, \\ Radboud University Nijmegen, Netherlands \\ b.hendrikx@ru.nl \\ ${ }^{\dagger}$ Institute for Management Research, Radboud University Nijmegen \\ *Geography, Planning and Environment, Radboud University Nijmegen \\ ${ }^{\S}$ Statistical Cybermetrics Research Group, University of Wolverhampton
}

\begin{abstract}
Slow Food (SF) is a global, grassroots movement aimed at enhancing and sustaining local food cultures and traditions worldwide. Since its establishment in the 1980s, Slow Food groups have emerged across the world and embedded in a wide range of different contexts. In this article, we explain how the movement, as a diverse whole, is being shaped by complex dynamics existing between grassroots flexibilities and emerging drives for movement coherence and harmonization. Unlike conventional studies on social movements, our approach helps one to understand transnational social movements as being simultaneously coherent and diverse bodies of collective action. Drawing on work in the fields of relational geography, assemblage theory and webometric research, we develop an analytical strategy that navigates and maps the entire Slow Food movement by exploring its 'double articulation' between the materialconnective and ideational-expressive. Focusing on representations of this connectivity and articulation on the internet, we combine methodologies of computation research (webometrics) with more qualitative forms of (web) discourse analysis to achieve this. Our results point to the significance of particular networks and nodal points that support such double movements, each presenting core logistical channels of the movement's operations as well as points of relay of new ideas and practices. A networkbased analysis of 'double articulation' thus shows how the co-evolution of ideas and material practices cascades into major trends without having to rely on a 'grand', singular explanation of a movement's development.
\end{abstract}

Keywords GLOBAL SOCIAL MOVEMENTS, NETWORK ANALYSIS, NETWORKING PRACTICES 
Slow Food (SF) is a global, grassroots movement aimed at enhancing and sustaining local food cultures and traditions worldwide. Its goal is to 'combat people's dwindling interest in the food they eat, where it comes from and how ... food choices affect the world around us' (SF International 2015a). Slow Food developed in the 1980s as a protest against the growth of a 'fast-food culture' in Italy. Almost 30 years after its establishment, SF has evolved into a significant global movement that promotes sustainable, local and high quality food production and consumption around the world.

Alongside its strong political message, which the whole movement supports, SF is also characterized by internal diversity. SF groups and practices have emerged in more than 150 countries (SF International 2015a) and have adapted to and become embedded in a wide range of local contexts, taking different forms and fulfilling different roles. This internal diversity is (and has been) crucial to SF's survival. To make sure that its international political aims are valid, powerful and concrete, creative new practices and strategies are needed for diverse local contexts. The grassroots chapters of SF, named 'convivia', engage in activities associated, each in their own way, with SF's main political ambition to develop a food system that is 'good, clean and fair' (SF International, 2015d). Convivia are local autonomous groups that enjoy the conviviality of sharing meals and local food, building relationships with local producers, organizing tastings and exchanging views and ideas. They are, in effect, the movement's basic building blocks.

Traditionally, scholars have had difficulties in exploring transnational social movements (TSMs) as simultaneously coherent and diverse bodies of collective action (Crossley 2002; Diani 2000; Tilly 2001). The widespread reach and geographically dispersed character of TSMs, as well as the simultaneous influence that both grassroots activities and coordinating centres have on their course and direction, compound these difficulties. Recent work on social movement organization has shown that movements' centres do not necessarily define and structure their course (Haug 2013; Routledge et al. 2007). In fact, complex interactions occur between such drivers for coordination and a movement contains many flexible and undirected forms of innovation. To better understand these complex relational processes, we ask how does a social movement take shape and form? What is the role of these competing forces in movement development? How far is the reach and control of both these grassroots and centralizing tendencies?

To answer these core questions, we outline a theoretical and methodological approach that focuses on the 'double articulation' between expressive ideas and material practices in TSMs (DeLanda 2006; Massey 1994). Drawing on work in relational geography (Massey 2005), assemblage theory (DeLanda 2006) and webometric research (Thelwall et al. 2005), we use this notion to explore the complex relational processes shaping the SF movement. Double articulation focuses on how a movement's parts are bound together through a combination of material-connective processes of interaction and association, and ideational-expressive processes of coding and signification. We use the notion of double articulation in particular to draw attention away from the supposedly stable social movement attributes and essences (organizational structure, hierarchy, best practices, identity and mobilized resources) 
that the social movement literature so frequently assumes (Chesters and Welsh 2006; Lockie 2004) and highlight instead the relational dynamics of movement 'becoming'. A second aim is to contribute to these challenges methodologically. We use a novel combination of webometric and semantic analysis to explore social movement data on the internet. First, we explain the notion of double articulation and our methodology before moving on to discuss our case study.

\section{Exploring the double articulation of social movements}

Social movements are complex forms of political action in which heterogeneous grassroots groups of actors coalesce around certain collective ambitions and joint political goals. Yet, this collective identity is not necessarily a well-defined and stable 'global authenticity' (Massey 1994), a homogeneous movement-wide meaning or identity that may be used as a top-down point of reference to which all social movement participants adhere. Instead, social movements acquire meaning and identity in continuous, dynamic processes in which their different grassroots parts relate, resist, discuss and debate the roles, identities and practices that circulate within a movement. Movements thus take shape in processes that simultaneously invoke diversity and coherence.

Focusing on the relational dynamics of double articulation helps us to deal with a key problem in the field of social movement studies. This is exploring what Diani called 'the fundamental characteristic of social movement experience', namely 'being part in a conflict which is at the same time embedded in specific, local orientations, interest, identities, but at the same time exceeds their boundaries, while maintaining the freedom and individuality of specific actors' (Diani 2000: 8). Double articulation allows us to zoom into this tension. The 'double' in double articulation refers to the reciprocal constitution of the material-connective and ideational-expressive. In material-connective terms, a global social movement is constituted by the way in which people, practices and resources circulate and interact through multi-spatial networks, operating both at the centre and the grassroots of the movement. It highlights the ways in which these heterogeneous elements are bound together into a single collective and give a movement a particular shape, form and meaning. This connectedness can be further understood through the second articulation in which ideational-expressive processes of meaning making and identity formation give meaning to a movement's practices and activities. Through specific ideas and signifiers, which are open enough to allow many other ambitions to attach themselves to it, a movement's collective and individual meaning and identity takes shape and form. These signifying activities occur at many places simultaneously and operate at the movement's core, centre and grassroots fringes. Sometimes, these show elements of coherence; at other times they indicate flexibilities and creativities that help to diversify the movement.

In this article, we develop a way of exploring the processes of double articulation in social movements through internet research. To do so, we use a novel combination of webometric analysis, different forms of web analysis and discourse analysis. We use webometrics to examine the material-connective side of Slow Foods articulation. How is the movement brought together? What material-connective relationships are forged? 
From what directions do they emerge? We use discourse analysis to focus more strongly on the movement's ideational-expressive articulation. What are Slow Food's key expressions in terms of meanings and identities that are articulated on the websites under study?

\section{Using the internet as a (big) data source}

A key challenge for the study of TSMs is that it is almost impossible to capture a movement in its entirety. The sheer size of the traces and interactions between a TSM's numerous and widely diffused groups make it almost impossible to understand how a movement is materially and/or organizationally connected. Traditionally, SM studies has tended to circumvent this by doing 'representative' case studies on a subset of Slow Food groups, or by focusing on how a movement has been organized and coordinated from a more central level (sources). Yet, when exploring the simultaneous difference and coherence of a TSM, this research strategy, in our view, fails to do justice to the full complexity of transnational movement development. To prevent this, we aim to build on the internet presence of social movements. While not suggesting that the online world is an objective representation of offline practices (see the section on limitations below), we treat it as an integral aspect of social movement practice and will use it as a useful entry point to explore how a movement is internationally connected.

\section{Webometric analysis}

A basic feature of the internet is that it allows individual webpages to 'interlink' (Almind and Ungwersen 1997: 406). Webometric analysis offers an effective and efficient means of exploring this interlinking (Thelwall et al. 2005). A key webometric research strategy is to 'crawl' and explore websites to generate a picture of their mutual interactions and relations. This permits a 'multi-site' analysis that easily moves from place to place, from website to website and from interaction to interaction (cf. Beaulieu 2010), which is particularly useful for the analysis of social movements that have a broad geographical scope.

To establish the corpus for our web-link analysis, we conducted several rounds of web crawling to identify individual SF websites around the world. ${ }^{1}$ Besides web crawling, we used manual strategies of 'snowballing' and manual web queries (conducted with Google and Bing) to complement the corpus. Official lists of convivia (local SF groups), national SF organizations and other related sites presented on the websites of the movement's umbrella organizations (such as slowfood.com) provided the input for the initial rounds of web crawling and snowballing.

The result of this analysis is a corpus containing 791 individual websites for local SF groups and organizations. The majority of these (728) are from local chapters and national SF associations. The others (63) consisted of earth markets ${ }^{2}(21)$, special activity branches - Cittaslow (15) and Terra Madre (3) - and a movement branch dedicated to youth, namely the Youth Food Movement (8). The 'other' category also includes a set of individual websites that transcend local chapters and act more as umbrella organizations for the movement on a whole (SF international, Salone del Gusto, and so on). 
We used webometric software (SocSciBot and WebometricAnalyst) to 'crawl' and map the corpus. The data thus gathered were used to create a relational picture of the movement by employing counts of the number of in-links and out-links between specific websites and clusters of websites (as detailed in the analysis below).

\section{Limitations of web-link analysis}

A key assumption of webometric analysis is that links have an 'information side-effect' and come with specific 'sociological meanings' (Hsu and Park 2011:364) that may be used to consider offline relationships (Adamic and Adar 2003: 211; Halavais 2008: 39). Although there is much research to support this basic idea (Ackland and Gibson 2006; Hsu and Park 2011; Vasileiadou and van den Besselaar 2006), including the fact that geographic relationships can be visible online (Thelwall 2002), findings are not 'objective' reflections of an offline social reality, so we should not overestimate their significance (Hine 2005). Rieder and Röhle (2012) consider the issue of overstated 'objectivity' as a key challenge surrounding internet research. This, along with the overpowering impact that (inter)network-visualization tools tend to generate, may lead too easily to 'totalizing worldviews' and 'all-embracing global pictures of social reality' that neglect the many internal diversities of which these online worlds are a part (Rieder and Röhle 2012).

It is in this respect that we should treat one of the key strategies used in webometrics with particular caution, namely the use of automated web-crawling techniques to gather large-scale data on links. As De Maeyer (2013) notes, since the objectivity of links and their relationship with offline practices is not to be taken for granted (see also Gillespie 2010), 'the automatic treatment and interpretation of a large amount of links may therefore become delicate'. To respond to this challenge, we have developed a mix of automated forms of web crawling, manual processing techniques, interpretative research and traditional 'offline' methods such as participatory research. We do not claim that our webometric findings resemble a perfect 'offline' reality as such, but rather view our findings as a subjective gateway, or panorama, to give us a stronger overview of the movement, which we use as an entry point for further research into difference and coherence. Moreover, the significance of our webometric findings will be tested by juxtaposing these results with the semantic analysis, that is, the other part of 'double articulation'.

\section{Semantic web analysis}

To explore the ideational-expressive dimensions of SF's articulation and to contextualize the finding of the webometric analysis, we develop a form of semantic analysis ${ }^{3}$ tailored specifically to unravel the different roles and identities expressed on SF websites. This starts with the identification of the nodal points of a semantic web, which entails outlining the key concepts, expressions and notions that help structure its meaning (Glynos and Howarth 2007). Nodal points are often key signifiers, such as 'democracy', 'sustainability', 'healthful', that in themselves are open to multiple interpretations. The meaning of these elements is made more specific by their relation 
to other concepts, ideas and expressions. The analysis of nodal points thus focuses on the ways in which these 'key signifiers' attach themselves to some meaningful elements (signifiers) while distancing themselves from others. Subsequently, our semantic analysis examines the ways in which relations between signifying elements involve inclusions and exclusions of particular forms of meaning. By analysing the 'chains of signification' (Glynos and Howarth 2007) that emerge from these associations, we get a clearer picture of the identities and 'subject positions' of the agents under study.

The websites were (manually) coded and recorded into a large database detailing core attributes ranging from daily activities to strategic political ambitions, from mission statements to international interactions (see below). To align the coding practices of multiple researchers, we established a detailed codebook and held recurring calibration sessions on coding and analytical interpretations. Extracts from the original website texts qualitatively substantiate each entry. Empirically, since our interest is in the double articulation of SF as being both coherent and diverse, the semantic analysis will focus on the ways in which, across SF websites, SF meaning and identity show certain global commonalities on the one hand and display local/regional differences on the other. This is also an issue of the relative position of particular groups, identities and activities in SF networks on a whole.

Table 1: Attribute database

\begin{tabular}{|c|c|c|}
\hline General and organization & $\begin{array}{l}\text { Programmes, projects, } \\
\text { campaigns }\end{array}$ & $\begin{array}{l}\text { Mission, ambition and } \\
\text { identity }\end{array}$ \\
\hline $\begin{array}{l}\text { Website details } \\
\text { (name, URL) }\end{array}$ & $\begin{array}{l}\text { Political activity, resistance } \\
\text { and activism }\end{array}$ & Slogans and symbols \\
\hline $\begin{array}{l}\text { Geography (place, } \\
\text { latitude/longitude) }\end{array}$ & Education and knowledge & $\begin{array}{l}\text { Ambition, mission and } \\
\text { orientation (mission text, } \\
\text { historical references) }\end{array}$ \\
\hline \multirow[t]{2}{*}{$\begin{array}{l}\text { Scope (international, } \\
\text { national local) }\end{array}$} & Entertainment, pleasure & \\
\hline & Environment and health & \\
\hline $\begin{array}{l}\text { Organizational structure: } \\
\text { frequency of meetings; type } \\
\text { of meetings }\end{array}$ & $\begin{array}{l}\text { Food traditions and cultural } \\
\text { heritage of food }\end{array}$ & \\
\hline \multirow[t]{4}{*}{ Resources and registries } & Food types & \\
\hline & $\begin{array}{l}\text { Networking and international } \\
\text { orientation of SF }\end{array}$ & \\
\hline & $\begin{array}{l}\text { Policy and government } \\
\text { oriented activities }\end{array}$ & \\
\hline & $\begin{array}{l}\text { Bridging food production and } \\
\text { consumption }\end{array}$ & \\
\hline
\end{tabular}

To characterize each of the SF groups/websites under study, we have matched the database records to the three steps of the semantic analysis outlined above. We have 
focused on three specific clusters of websites. The first of these is SF International, which we chose because it presented one of the most central sites in the whole corpus of SF websites, as evidenced in the webometric phase of the research. The second is SF in the USA, selected because it forms a large and relatively independent cluster in the corpus, and is seen as a fast growing, diverse and innovative part of the SF movement (Organic Consumers Association 2001). The third and final one, SF Netherlands, is relatively independent of SF International because of its organizational form and identity. Besides this, its key practices show an articulation of SF that is different from those expressed by either SF International or SF in the USA. This contributes to the study's emphasis on and understanding of movement diversity.

\section{Findings}

\section{SF's material connectivity}

In our analysis, SF appears to be strongly connected online. It signifies a modern transnational social movement, with many references and links on the internet, and well interconnected sites. Most of the individual sites (94.2 per cent) had links with others in the set. This is evidence of the connectedness of the movement in itself. Figure 1 below shows the connections between websites that are part of the corpus.

Figure 2 shows the SF movement from a bird's eye perspective and highlights some of its main features. We see that some central sites appear and that national SF groups cluster together.

In terms of centrality, the analysis shows that certain sites are more often referenced than others. These can be traced on the map, but are also shown in the quantitative data offered by the web analysis software. The list of the most connected sites (Table 2) shows that the international association (slowfood.com), the national association of the USA (slowfoodusa.org) and SF Italy (slowfood.it) have received most links from other SF websites in the dataset.

When we zoom in onto specific geographical regions, we see that there is much more interlinking between sites of the same nationality. This can partly be explained by the organizational set-up of SF in specific countries. Countries such as Italy, Germany, Switzerland, the Netherlands and Brazil have an organizational structure at the national level. The majority of convivia, however, fall directly under the international SF headquarters.

The most central SF website is slowfood.com, a site that is registered by the international headquarters of SF in Italy. The centrality of slowfood.com is derived from the large number of in- and out-links to and from other SF websites in our corpus (total 361; $\mathrm{n}=792$ ).

The material connective centrality of slowfood.com is also confirmed qualitatively by descriptions of the international organization on various websites within the corpus. Slowfood.com itself indicates that its role is one of 'planning and promoting the development of the SF network and of SF projects worldwide' (SF International 2015c). A number of 'key' political programmes are strongly endorsed on the international organization's website: 
Figure 1: SF internet connectivity. Corner nodes are unconnected sites (mainly Facebook)

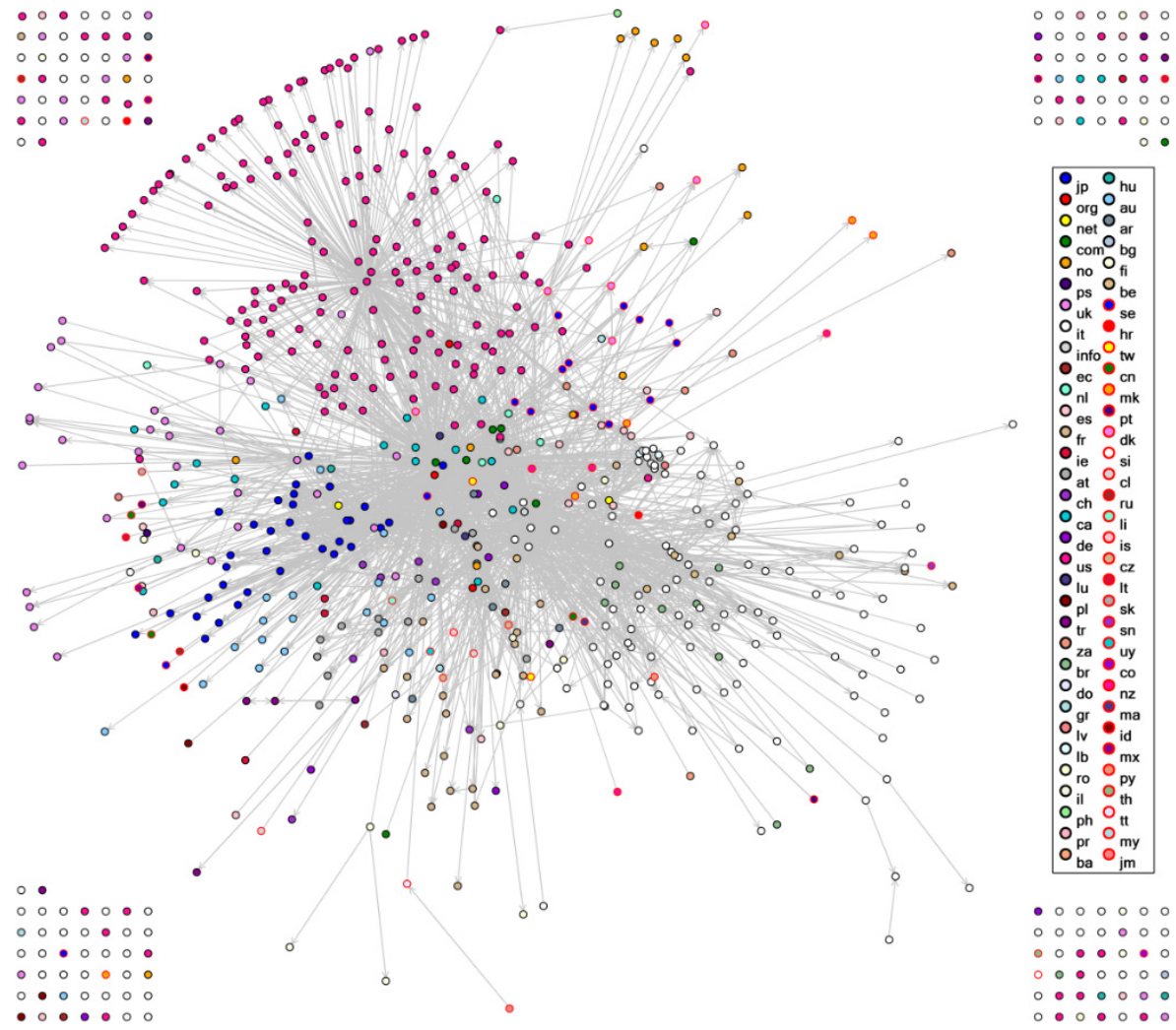

Table 2: Most connected sites

\begin{tabular}{lrrrrrrrr}
\hline Name* & $\begin{array}{c}\text { In } \\
\text { degree }\end{array}$ & $\begin{array}{c}\text { Out } \\
\text { degree }\end{array}$ & $\begin{array}{c}\text { Degree } \\
\text { Min }\end{array}$ & $\begin{array}{c}\text { Degree } \\
\text { Max }\end{array}$ & $\begin{array}{c}\text { Degree } \\
\text { Total }\end{array}$ & $\begin{array}{c}\text { Indegree } \\
\text { Binary }\end{array}$ & $\begin{array}{c}\text { Outdegree } \\
\text { Binary }\end{array}$ & $\begin{array}{c}\text { Degree } \\
\text { Binary }\end{array}$ \\
\hline slowfood.com & 341.000 & 28.000 & 348.000 & 348.000 & 369.000 & 341 & 28 & 348 \\
slowfoodusa.org & 175.000 & 170.000 & 223.000 & 223.000 & 345.000 & 175 & 170 & 223 \\
slowfood.it & 154.000 & 47.000 & 162.000 & 162.000 & 201.000 & 154 & 47 & 162 \\
slowfoodfoundation.com & 76.000 & 49.000 & 112.000 & 112.000 & 125.000 & 76 & 49 & 112 \\
terramadre.info & 108.000 & 1.000 & 108.000 & 108.000 & 109.000 & 108 & 1 & 108 \\
unisg.it & 102.000 & 7.000 & 106.000 & 106.000 & 109.000 & 102 & 7 & 106 \\
slowfoodstockholm.se & 5.000 & 85.000 & 89.000 & 89.000 & 90.000 & 5 & 85 & 89 \\
slowfood.com.tw & 8.000 & 65.000 & 71.000 & 71.000 & 73.000 & 8 & 65 & 71 \\
slowfoodjapan.net & 28.000 & 61.000 & 68.000 & 68.000 & 89.000 & 28 & 61 & 68 \\
slowfish.it & 59.000 & 2.000 & 60.000 & 60.000 & 61.000 & 59 & 2 & 60 \\
salonedelgusto.it & 57.000 & 4.000 & 59.000 & 59.000 & 61.000 & 57 & 4 & 59 \\
slowaichi.net & 8.000 & 56.000 & 58.000 & 58.000 & 64.000 & 8 & 56 & 58 \\
slowfood.fr & 44.000 & 30.000 & 55.000 & 55.000 & 74.000 & 44 & 30 & 55 \\
slowfood-friends.org & 13.000 & 44.000 & 51.000 & 51.000 & 57.000 & 13 & 44 & 51 \\
\hline
\end{tabular}

${ }^{*}$ Centrality $=0.0105$, directed centrality $=0.0061$. 
Figure 2: SF sites clustered by country

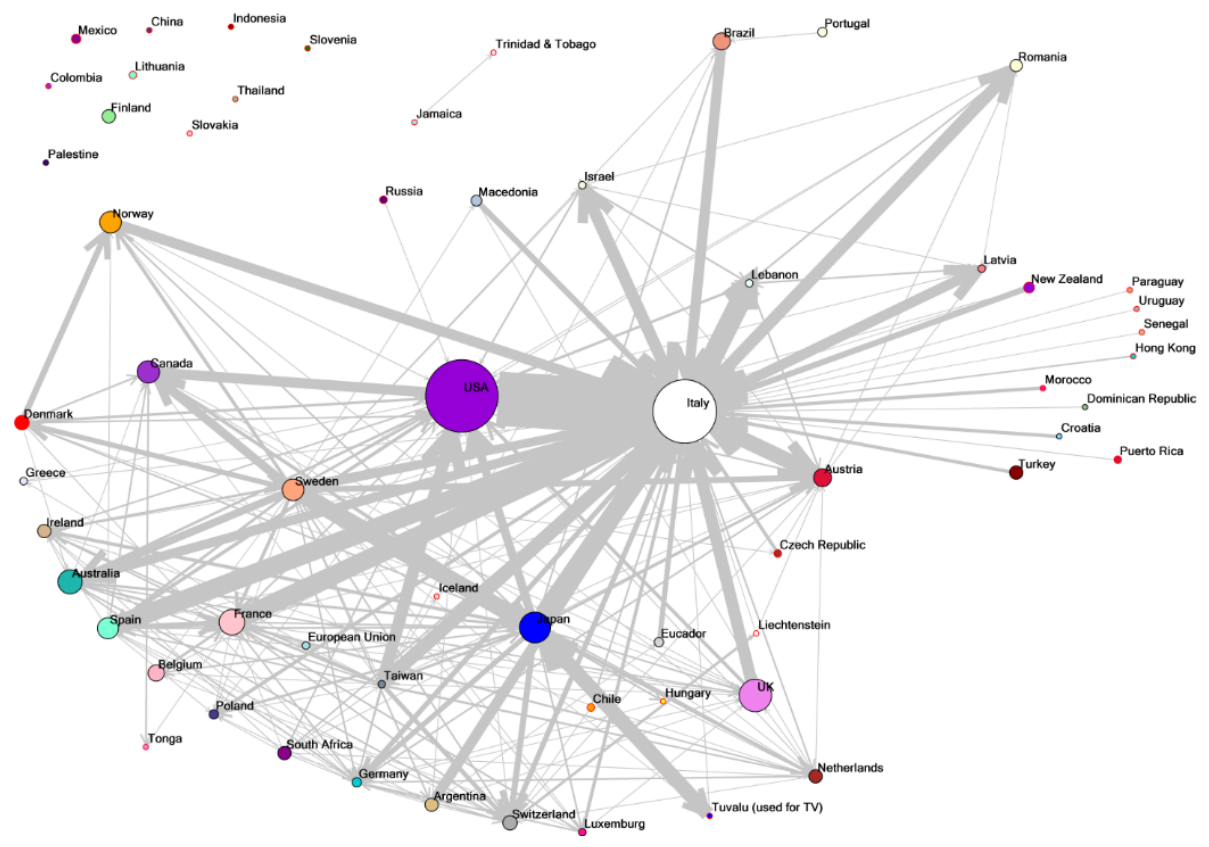

- the 10,000 Gardens in Africa (a worldwide project to develop 10,000 SF gardens in Africa);

- the Ark of Taste (a global project to collect and record small-scale quality productions that belong to specific cultures, histories and traditions);

- Stop TTIP (a political campaign with 300 other European NGOs against an upcoming trade agreement);

- Slow Fish (a political campaign for a more sustainable fish system);

- Terra Madre (an international network of SF communities); and

- Earth Markets (a worldwide network of farmers' markets respecting the SF philosophy).

Regional and local connectivities: details of the USA and Dutch SF

The webometric network analysis also provides a way to zoom onto specific regional clusters and densities. Zooming onto these clusters enhances our understanding of the movement's internal makeup and diversity. As discussed above, we will focus our analysis here on the USA and the Netherlands.

\section{Clustering in the USA}

Almost all the sites that interlink within the USA corpus, link to the national SF organization; this emerges as the most central site in the corpus (an in-degree of 58 from 79 sites). This also reflects the organizational structure of SF in the USA, since all US convivia fall under the national umbrella organization. There is considerable connectivity among US convivia, as there is also between US convivia and the 
international branches of the movement. In particular, the convivia sites mention the sites of SF International, its associated Terra Madre project and to a lesser extent the SF Foundation. This illustrates that many US convivia feel a very strong sense of affiliation to the international movement.

We will use this analysis of the material connectivity of the US SF as an entry point for the qualitative analysis of the ideational-expressive articulation of SF in the USA in the sections below. In that analysis we explore how the national organization, the key nodes (such as 'Snail of Approval', explained below) and the grassroots sites of the movement are enrolled in the articulation of US SF identity.

\section{Figure 3: Material connectivity of SF USA}

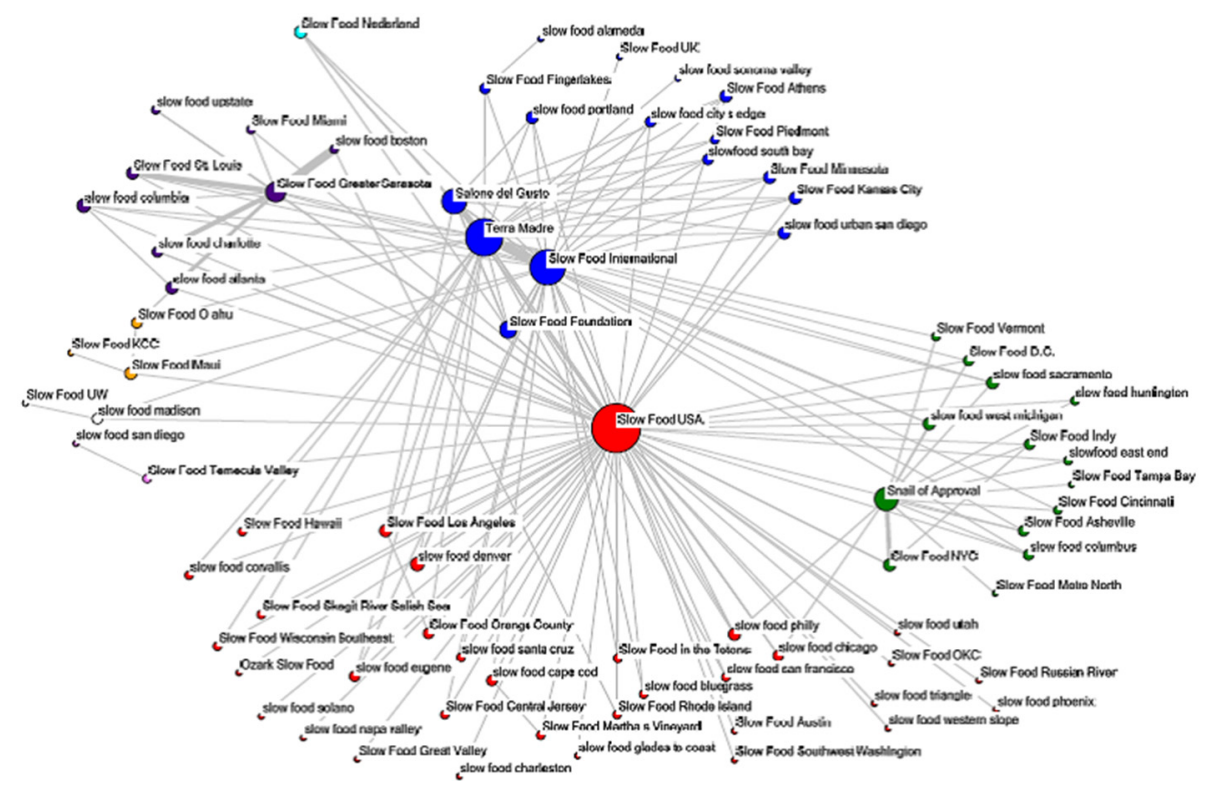

\section{The Dutch SF cluster}

The Dutch corpus is much smaller (22 sites) than the US one and its convivia websites are all part of the national one. The national SF organization emerges as the most central website (slowfood.nl) in the web-link analysis, which also reflects its organizational role in the Dutch movement. More than in the USA, however, interactivity between Dutch SF convivia follows lines of geographic proximity. Convivia in the Achterhoek, Arnhem-Nijmegen; in the northern Netherlands, Zwolle and Drenthe; and in Rotterdam, Groene Hart and Den Haag, have several mutual links. Some of these regionally proximate convivia also organize joint activities.

Links between Dutch convivia and SF International are rather loose. Although many link to the 'Terra Madre' project, the connection is often only to do with a recurrent local event that the Dutch convivia organize to celebrate the birthday of the SF movement (Terra Madre Day). We have found little evidence of any actual interaction with SF International's political Terra Madre project (see content analysis below). Other 
convivia refer to SF International to highlight that they are part of a larger, international body, yet little substance and context is given for these links. In general, the interconnectivity of the Dutch SF appears to be meagre.

A different pattern emerges for the national SF organization, for its website features worldwide SF projects such as the Presidia, the Thousand Gardens Project and, in particular, the Ark of Taste. On the latter, reference is made to several initiatives, including an Ark committee, to enable more Dutch products to acquire Ark or Presidium status. What appears is a hub-and-spoke pattern, in which SF's more global ambitions are met at the national level.

\section{Figure 4: Material connectivity of Dutch SF}

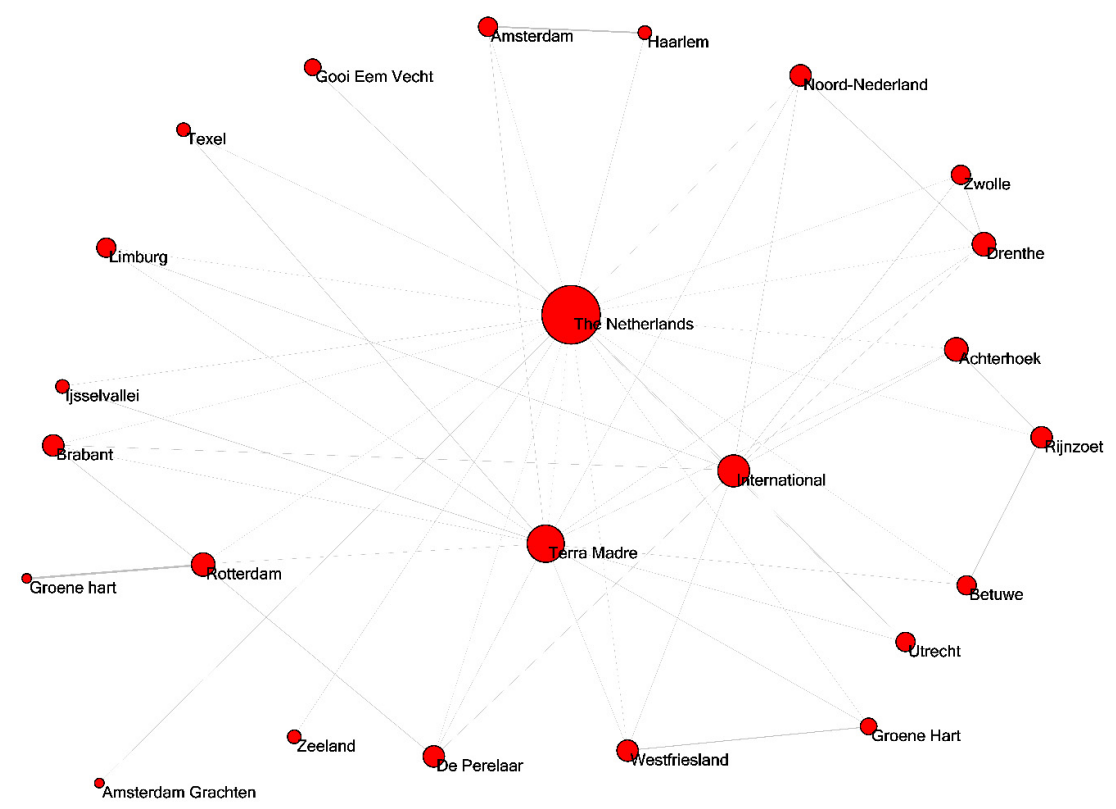

SF's ideational-expressive articulation

To make sense of these patterns of material connectivity, we now move to the second phase in the analysis of SF's double articulation. Employing semantic web analysis, we first explore SF's 'central sites' (SF International) and then look into how roles and identities are articulated in its two grassroots clusters in the USA and the Netherlands.

Central sites: an expressive analysis of the drive towards movement harmonization As the movement's main organizational headquarters, SF International (slowfood.com) is concerned with setting out, planning and aligning the global ambitions and activities of the movement as a whole. Particularly important is the meaning that slowfood.com attaches to the key signifier 'SF'. On its websites, slowfood.com uses four 'key signifiers' that code SF as a concept and practice. These signifiers appear in different forms and enunciations across its website: 
- $\mathrm{SF}$ is about 'biodiversity';

- SF is 'against industrial and low-quality food' and is about connecting 'consumers and producers';

- SF builds on 'social/ convivial' practices; and

- $\mathrm{SF}$ is about 'preserving knowledge and engaging in education' about our food system

SF's 'good, clean and fair' slogan can be seen as a key signifier that binds these different statements and identities together under the overall SF concept.

Each of the four key signifiers in the slowfood.com discourse is made more specific through its relation with other concrete concepts and practices. These relationships become visible most clearly in the global projects, campaigns and programmes advocated by SF International, as shown below:

Table 3: Key signifiers of SF International

\begin{tabular}{ll}
\hline Key signifier & SF International project(s): \\
\hline biodiversity & Ark of Taste, Slow EU campaign, Slow Fish \\
against industrial and low-quality food, & Ark of Taste, Slow EU campaign, TIPP/CETA, \\
and consumer-producer relationships & Slow Fish, convivia, Ark of Taste/Presidia \\
social/convivial & $\begin{array}{l}\text { convivium as organizational building-block/ } \\
\text { Thousand Gardens project } \\
\text { knowledge and education }\end{array}$ \\
\hline
\end{tabular}

'Biodiversity': Ark of Taste and political campaigning The concepts of 'biodiversity' and 'against industrial food' are a main feature in the 'Ark of Taste' and 'Presidia' programmes. SF HQ founded the Ark of Taste in honour of the first Salone del Gusto (a key SF producer and product feature market) in Italy. The Ark of Taste is SF's main international project aiming to register and preserve 'small-scale quality productions that belong to the cultures, history and traditions of the entire planet' (SF Foundation 2015b). The aim of the Ark of Taste is to catalogue (scientifically) and promote food products, breeds and crops that are on the verge of extinction. After the successful development of the Italian Ark, the project was extended to other countries, first the USA and Germany, later Switzerland, the Netherlands and France (SF Foundation 2015d). The 'Presidia' project is closely associated with the Ark project and aims to 'sustain quality production at risk of extinction, protect unique regions and ecosystems, recover traditional processing methods, safeguard native breeds and local plant varieties' (SF Foundation 2015c).

'Against industrial food' and 'enhancing consumer-producer relations' A number of SF International projects are of a more political character. Projects such as SF's 'Slow Fish campaign', the 'Slow Europe' project, and a joint NGO initiative against the TTIP 
and CETA trade agreements, aim to campaign for change in the 'food system' by advocating for a more sustainable (and less industrial/polluting) cycle of food production. These projects link SF International's 'biodiversity' goals to its 'against industrial food' goals and often include a social/human dimension.

SF International emphasizes that a key potential of political change in the food system is through enhancing the relationships between producers and consumers. Recently, SF has coined the term co-producer as an alternative to the term 'consumer' to indicate the active role consumers can play in the food system. Convivia may play a key role in this, as it serves as a meeting place for local/regional consumers and producers.

Knowledge and education: Thousand Gardens and Terra Madre The 'knowledge and education' signifiers of SF are clearly expressed in the 'Thousand Gardens in Africa' project. This project binds together the biodiversity ambitions of SF, its social and development goals and most prominently its knowledge and education objectives. With the Thousand Gardens project, SF aims to (1) set up a network of young people to preserve and support biodiversity in Africa, (2) raise the profile of traditional knowledge and food culture in Africa, and (3) promote small-scale, family farming (SF Foundation 2015a).

A different project that also focuses on knowledge and information exchange is the Terra Madre project. Terra Madre offers an international platform for networking, the sharing of best practices and knowledge-development to connect 'local communities ... working to establish a system of good, clean and fair food from the grassroots level' (SF International 2015b). The aim of Terra Madre is to link up local solutions and struggles across the globe and to strengthen them through facilitating (international) exchange and dissemination.

Conviviality A key code of both SF's identity and practice is the convivium. The notion of the convivium and convivial practice as the grassroots building blocks is mentioned frequently on the slowfood.com website. It emphasizes the social and collective aspects of SF as an identity both locally and globally. Through various means of international collaboration and collective action, local chapters are able to express their conviviality on a much larger and international scale. The Terra Madre project for instance aims at knowledge exchange between different producer communities, and the Thousand Gardens in Africa project allows Northern convivia to support local groups in Africa. Figure 5 visualizes the ideational-expressive articulation of SF HQ.

\section{SF meaning and identity from the grassroots}

We shall now focus on the expressive articulation of SF from a regional perspective. The main query here is to look into the differences and similarities between the meaning and identity of SF in two different regional contexts and those expressed by SF HQ. We draw here on our semantic analysis and the database with ideational expressive data about SF practices across the USA and the Netherlands. 
Key signifiers of SF USA SF USA has more than 170 local convivia and a membership of around 12,000 people. In our corpus, it is represented by 151 websites. SF USA has an overarching national chapter that takes care of membership administration and organization, and provides a link between the convivia and SF International.

\section{Figure 5: Ideational-expressive articulation of SF HQ}

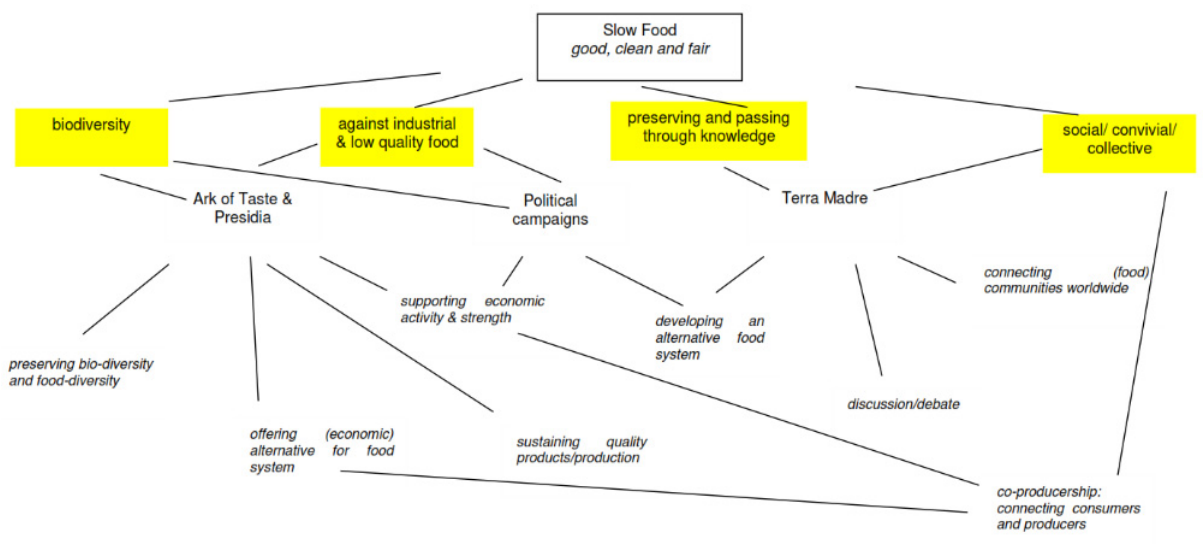

Biodiversity Many US convivia websites refer to the theme of 'biodiversity' as a key part of SF identity and meaning. Roughly a third of the US websites explicitly refer to the theme. Most of those references (38 per cent) are mission statements or referrals to biodiversity as a theme for SF in general. Fewer USA convivia (22) have an explicit active engagement with the theme through actual events and activities. Such activities are often in the form of debates, discussions and lectures. A few US convivia (11) move beyond mere discussions on the theme and engage in activities that actively focus on enhancing local biodiversity. Examples are the 'Saving Seeds for Biodiversity' project of SF Russian River, and the 'Endangered Vegetable Project' of SF Wisconsin Southeast. SF convivia in the USA also interact with the biodiversity theme through international SF projects (most notably through the Ark of Taste and Presidia ones). A quarter of all 151 US convivia discuss the Ark project on their websites. Of these, 27 indicate a more active engagement, for example by showcasing Ark of Taste and Presidia products at their convivia dinners, by actively supporting farmers and producers who are (or want to be) part of the Ark, or by endorsing products from within the region as a possible Ark product. Innovative practices that deal with biodiversity via the Ark of Taste project are various 'seed exchange' and 'gardening' projects (SF Huron and Utah). There are also several fundraising projects and micro-grants aiming to support Ark and Presidia product producers (SF St Louis). Overall, US convivia seem solidly engaged with the theme of biodiversity and in particular the Ark of Taste.

Anti-industrial US convivia also engage with the 'anti-industrial' identity of SF, often as an essential part of their mission and ambition as an SF group. Some groups 
actively organize meetings, discussions and projects revolving around the theme. Frequently, when sites discuss the difficult relationship between the industrial food sector and environmental sustainability, food safety and the cultivation of food traditions, a link is made between the 'anti-industrial' signifier and the theme of 'biodiversity'. Activities organized around the theme often have a political and educational character and range from public film screenings, lectures on artisanal and more sustainable ways of food production, to the active promotion of organic and non-industrial forms of breeding and plant cultivation. Several US convivia have set up and support anti-GMO screenings, protests and campaigns, and the support of local farmers and producers that use only GMO-free resources.

Enhancing relations between producers and consumers Many SF USA groups proactively reach out to producers that are not part of the industrial food system. This is done in diverse ways, ranging from groups of SF volunteers who help local farmers with their harvests, SF groups endorsing local products at regional food markets, groups fundraising for local Ark of Taste producers, and groups that display local products or producers at regular convivium meetings. Regional, earth and SF markets also play an important role in connecting consumers to producers that adhere to the SF philosophy. A key project currently being rolled out throughout the USA is the Snail of Approval. Local SF groups give Snail of Approval qualifications to restaurants, bars, food and beverage producers, stores and markets for 'their contributions to the quality, authenticity and sustainability of their food supply' (SF NYC n.d.). Website directories created specifically for this project help local consumers to connect with local 'good, clean and fair'.

Knowledge exchange and education Education and schooling is a dominant theme for US convivia. In the USA, 35 per cent of all convivia websites indicate that they are involved in bringing SF ideas and values to schools and children. They see education as 'the first step in gaining the appreciation that can lead to preservation' (SF USA 2015) thus gaining support for SF's more general goals of sustainability and enhancing biodiversity. A key way in which this is done is through school gardens. As a project the national SF organization initially devised in 2001 to enhance food and taste education, School Gardens are now an omnipresent tool used by 34 SF groups to connect to their local communities across the USA. A different element of SF's 'knowledge and education' signifier is exchanging knowledge about food products, food preparation skills and food traditions within local convivia. These are largely internal events, with some regular activities oriented towards a broader public (including SF festivals, markets, film screenings and public debates and lectures, for instance on health and obesity).

Politics and activism Besides child nutrition, health and obesity, US convivia also deal with other important political themes associated with food. Many convivia engage in political campaigns directed against the big food industry, environmentally unfriendly fishing and unsustainable forms of food production in general. A recurring theme is the battle of SF in the USA against agrochemical and agricultural biotechnology companies, notably Monsanto. SF has organized many protest marches, social media campaigns and direct action against Monsanto. 
Social, convivial and community building A cornerstone of SF practices in the USA is 'conviviality' and community building. SF groups are largely set up around the convivial practices of cooking and eating together, often organized on a monthly or even weekly basis. US convivia are very much open to external involvement and focus strongly on the communities in which they are embedded. Not only do they connect with these communities by organizing public events (festivals, markets, films and so forth), but also through active support and volunteering (community gardening, school gardening, community supported agriculture, fundraising). What is remarkable is that gardening is often used as a tool to achieve this. Community and school gardens are both used to educate people about food, biodiversity and to bring (impoverished) communities together. Traditional convivial practices of jointly enjoying and sharing the pleasures of food are also still a key part of movement activities, but are strengthened by explicit forms of community outreach.

\section{Figure 6: Ideational expressive articulation of SF USA}

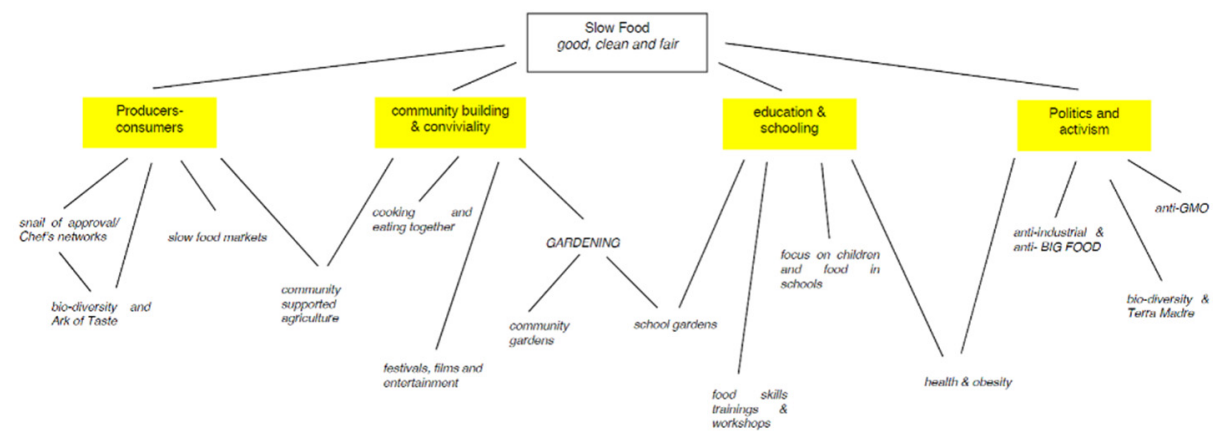

Key signifiers of Dutch $S F \quad \mathrm{SF}$ in the Netherlands is an outlier within the international SF community. It forms a relatively small subset of our whole corpus, and includes one general site (slowfood.nl) and 20 convivium sub-sites. SF the Netherlands is also different in organizational terms. Whereas convivia in most other countries fall directly under SF headquarters in the Italian town of Bra, SF in the Netherlands has a national chapter that represents and organizes its local convivia. This makes local Dutch convivia relatively more independent from the visions and missions of Bra, and, against this background, an interesting case for analysis.

Biodiversity To explore Dutch SF engagement with biodiversity, we looked for explicit references to a group's ambition to learn about, stimulate and enrich the biodiversity of their (local and global) environments through food related practices. Only seven of the 19 convivia sites refer to biodiversity in relation to SF. Most of these are merely a reference to biodiversity as one of the general SF ambitions. A few have engaged more explicitly with the notion by organizing a lecture or film screening on the topic. Only two of the 19 convivia have organized concrete activities aimed at stimulating biodiversity: one group has set up a community garden to enhance the local urban biodiversity another has focused on supporting and further strengthening typical 
regional food products at an international level. The expressed participation of Dutch convivia in international SF projects associated with the key signifier 'biodiversity' (namely, Ark of Taste, Presidia) is also thin. While 12 of the 19 sites refer to Ark or Presidia projects, as in the USA, most of them only refer to the Ark of Taste as a general SF project. The few convivia with an explicit engagement with the project do so in terms of putting one Ark or Presidia product on the menu of a local convivium's potluck or restaurant dinner, or by featuring an Ark product in one of its product showcase sessions. Overall, there is no strong or explicit external political commitment to the theme of biodiversity expressed on Dutch convivia websites.

Anti-industrial Dutch convivia show limited interest in opposing industrial or fast foods. The most explicit reference to the theme has been made by a single convivium (Rijnzoet) in its endorsement of a local organic butcher. Another convivium briefly touches on the theme in a blog post by mentioning the differences between industrial and artisanal bread. Only one convivium adds more substance to its engagement with the theme by organizing a lecture on the negative impact of food additives and Enumbers.

A stronger focus on producer-consumer relations Most convivia and the national SF organization express 'the relation between consumers and producers' as one of the key ambitions of Dutch SF. SF aims to 'support local products' and, more importantly, 'small-scale local producers' (SF Netherlands n.d.). SF groups do so by establishing networks between producers, both on a regional and national scale, and between consumers and producers, often within convivia themselves. In fact, Dutch convivia membership often consists of an intricate mix of producers and consumers. A key project in which the importance of this consumer-producer relationship becomes visible is the Chefs' Alliance. Although this project is not unique to the Netherlands (there are similar ones in Morocco, the USA and the UK), the Dutch project evolved from a 'grassroots' willingness and engagement of a few Dutch convivia (notably Utrecht) to connect producers, chefs and consumers more strongly to the SF philosophy. The main idea of the Chefs' Alliance is to bring producers and restaurant chefs together to highlight the quality, history and diversity of regional dishes and food products. Its core ambition is to use restaurants and chefs 'to help unique, endangered products and their small scale producers to survive in a food-system dominated by "Big Food"' (SF Netherlands 2014). The project builds strongly on the idea of SF as a movement that connects producers and consumers and that fights the industrial food system by supporting local small-scale production and consumption.

Knowledge exchange and education Most of the Dutch convivia engage in activities that focus on sharing and exchanging knowledge about food and food production. Unlike the SF HQ, which is more politically inspired and aimed at educating larger societal groups, Dutch convivia focus largely on their own network. Events, such as food workshops, joint cooking sessions and master classes concentrating on a specific product or cooking technique, are the key social events around which local convivia gather. Such workshops are organized throughout the Dutch network and form one of the landmarks of Dutch convivia events. A few educational events are organized for a larger audience, such as a farmers' market or SF film festival, which also feature 
workshops and product demonstrations that are open to the public. Perhaps somewhat more politically inspired are some of the lectures organized by Dutch convivia. Yet, even such events are often aimed at an internal audience (local convivium members), rather than at the Dutch public in general. Many of these lectures focus on one food product or production method (beekeeping, eating seaweed, insects as food, keeping sheep and so on). Only a very small group of convivia engages in knowledge exchange on a wider societal level. One convivium (SF Texel), for instance, directs its activities towards schools and children with projects such as 'the healthy school canteen', or a political campaign to rid restaurants of 'children's menus'. The aim of the latter project is to teach children about the qualities of 'real' 'grown up' food and to reject the traditional 'French fries' on children's menus.

Social, convivial and collective The common denominator for Dutch SF convivia is their convivial practices, namely enjoying and sharing food and drink. Almost all of them hold regular potlucks, cooking sessions and restaurant dinners with their members. In fact, these 'eating activities' seem to be the main type of event that Dutch convivia organize. This has attracted some criticism from the public, with one author calling SF the Netherlands an 'elitist eating-club of bon-vivants with a lot of money to burn' (Hoeben 2014).

Entertainment and enjoyment A third signifier that is strongly related to the epicurean character of Dutch SF is the notion of 'food as something that is entertaining and as something that should be enjoyed'. Several of the Dutch convivia organize food festivals, film festivals, tasting sessions and farmers' markets to share and enjoy the pleasure of engaging with food.

\section{Figure 7: Ideational expressive articulation of Dutch SF}

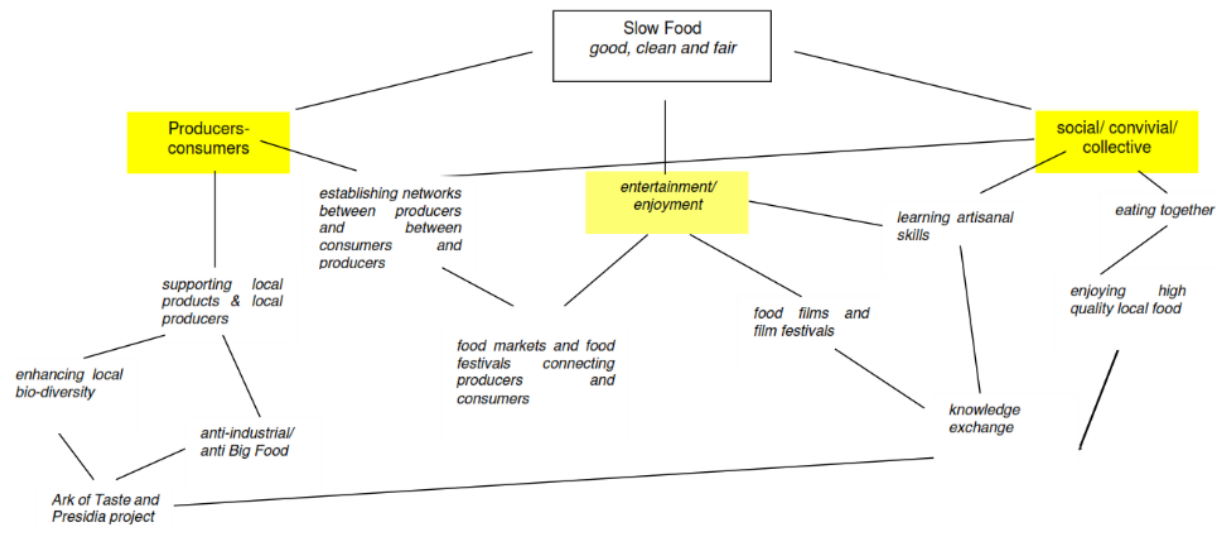

\section{Conclusion}

Since its emergence in the late 1980s, Slow Food has developed into a dynamic and well-connected body of collective action that is now able to make an impact in more than 150 countries across the world. To make sense of this vast and dynamic social movement, we have explored Slow Food with a non-traditional semiotic, relational approach that focuses on the movement's 'double articulation'. 
The first articulation lays bare the infrastructures of movement connection, focusing on a social movement as a topological network of links and joints. In our study we have focused primarily on the SF's web topology as a way of seeing important regional patterns and central clusters. Which are the centrally placed practices and nodes that seek to structure and organize the movement? How far does their influence reach into the grassroots of the movement? The probing of the second articulation reveals roles and identities in this movement topology, which provide the movement with direction. Here, the topology revolves around signifiers open enough to allow for adaptation and variable translation. Organizational attempts at making the movement more coherent and uniform have an impact, but are, in their circulation from place to place, adapted, multiplied and enrolled differently. For instance, whereas SF in the Netherlands remains rather epicurean and focuses strongly on their internal SF communities, SF in the USA is much more politically active and centred on strengthening and educating the communities in which they are embedded. Another key difference is that the internal coherence and interaction among US Slow Food convivia is far greater than those in the Netherlands. This chimes with the greater role attributed to movement politics and political movement identities in the USA, as signified in our 'ideational expressive' analysis of both parts of the movement

Crucially, a 'semiotic' network analysis as employed here presents a movement as, to quote Massey (2005), a 'multiplicity of stories so far' emerging in a material relational setting. Multiplicity corresponds with a dynamic constellation of joints and hinges making certain stories powerful, while others constitute a repertoire of past as well as potential future inspirations and wider circulation. Actual centres of control may seek to channel translation and circulation to some extent, but new ideas and practices continue to emerge and proliferate from different places within the movement. These concurrent drives in a global movement make it simultaneously coherent and diverse, harmonizing and fragmenting. Our analysis draws attention, in particular, to those nodal points that support such double movements, that help diverse, differentiated, initially marginal ideas to reach out, tying them to organizational hubs (such as SF International) and key signifiers ('good, clean and fair'). Nodal points are at the heart of processes of material connective circulation and expression which defy any simple conceptualization of a movement in terms of singular processes of agency or drives. This confirms the limited role played by centres of coordination and control. While always present in social movements in one way or another (Haug 2013; Routledge et al. 2007), such centres do not necessarily define and structure the course of a movement. Rather, structuring and stabilization result from the complex networking processes that foster as well as channel the inherent dynamism and grassroots creativity of such movements.

Finally, to reveal these developments, we have elaborated a methodological approach that is able to trace the difference and coherence of TSMs using webometrics and semantic web analysis. Although there are clear limitations to these forms of internet research, in this article we have shown that, by focusing on web connectivity and semantic links from individual websites, it is possible to 'make sense' of TSMs (cf. Crossley 2002). The results of this online analysis, however, should not be seen as full 
representation of the movement's offline reality. Instead, it offers an initial way of acquiring an overview of a geographically vast and internally diverse social movement, which might provide entry points for further more detailed accounts on a movement's articulation.

\section{Notes}

1. The initial search terms we employed were 'Slow Food', the various labels for key Slow Food practices such as 'Terra Madre' and 'Ark of Taste' (and their Dutch, German, Spanish, French and Portuguese equivalents) combined with the 'site:' parameter to search in different top-level domains (for example, 'site:.nl' for the Netherlands, 'site:.cd' for the DRC). Snowballing involved manually exploring the initial set of websites for links to other groups and practices.

2. Earth markers are local markets of fresh produce markets that follow Slow Food principles.

3. For a more detailed methodological exploration, see Jorgensen et al. (2002); Varró (2010).

\section{References}

Ackland, R. and R. Gibson (2006) 'Hyperlinks and horizontal political communication on the www', Virtual Observatory for the Study of Online Networks, Canberra, http://vosonlab.net/.

Adamic, L. A. and E. Adar (2003) 'Friends and neighbors on the web', Social networks, 25 (3), 211-30, doi: 10.1016/S0378-8733(03)00009-1.

Almind, T. C. and P. Ingwersen (1997) 'Informetric analyses on the world wide web: methodological approaches to "webometrics"', Journal of documentation, 53 (4), 404-26, doi: 10.1108/EUM0000000007205.

Beaulieu, A. (2010) 'From co-location to co-presence: shifts in the use of ethnography for the study of knowledge', Social Studies of Science, 40 (3), 453-70, doi: 10.1177/ 0306312709359219.

Chesters, G. and I. Welsh (2006) Complexity and social movements: multitudes at the edge of chaos, London: Routledge.

Crossley, N. (2002) Making sense of social movements, Buckingham: Open University Press.

DeLanda, M. (2006) A new philosophy of society: assemblage theory and social complexity, New York: Continuum.

De Maeyer, J. (2013) 'Towards a hyperlinked society: a critical review of link studies', New Media \& Society, 15 (5), 737-51, doi: 10.1177/1461444812462851.

Diani, M. (2000) 'Networks and social movements: from metaphor to theory?', paper for the conference 'Social Movements Analysis: The Network Perspective', Ross Priory, Loch Lomond, 23-25 June.

Gillespie, T. (2010) 'The politics of "platforms"', New Media \& Society, 12 (3), 347-64, doi: $10.1177 / 1461444809342738$.

Glynos, J. and D. R. Howarth (2007) Logics of critical explanation in social and political theory, London: Routledge.

Halavais, A. (2008) 'The hyperlink as organizing principle', in J. Turrow and L. Tsui (eds) The hyperlinked society: questioning connections in the digital age, Ann Arbor, MI: University of Michigan Press.

Haug, C. (2013) 'Organizing spaces: meeting arenas as a social movement infrastructure between organization, network, and institution', Organization Studies, 34 (5), 705-32, doi: 10.1177/ 0170840613479232.

Hine, C. (2005) Virtual methods, Oxford, Berg.

Hoeben, R. (2014) 'Slowfood op de inhaalstrook', NRC Handelsblad, 24 May, available at: www.nrc.nl/nieuws/2014/05/24/slowfood-op-de-inhaalstrook-a1473375. 
Hsu, C. and H. W. Park (2011) 'Sociology of hyperlink networks of Web 1.0, Web 2.0, and Twitter: a case study of South Korea', Social Science Computer Review, 29 (3), 354-68, doi: $10.1177 / 0894439310382517$.

Jorgensen, M. and L. Phillips (2002) Discourse analysis: as theory and method, London: Sage.

Lockie, S. (2004) 'Collective agency, non-human causality and environmental social movements: a case study of the Australian "landcare movement", Journal of Sociology, 40 (1), 41-57, doi: 10.1177/1440783304040452.

Massey, D. (1994) 'Double articulation: a place in the world', in A. Bammer (ed.) Displacements: cultural identities in question, Madison: University of Wisconsin, 110-22.

Massey, D. (2005) For space, London: Sage.

Organic Consumers Association (2001) 'Slow food movement grows across the USA: Slow Food gains fast acceptance among all breeds of consumers', webpage, available at: www.organic consumers.org/old_articles/Organic/slowfood.php.

Rieder, B. and T. Röhle (2012) 'Digital methods: five challenges', in D. Berry (ed.) Understanding digital humanities, Basingstoke: Palgrave Macmillan, 67-84.

Routledge, P., A. Cumbers and C. Nativel (2007) 'Grassrooting network imaginaries: relationality, power, and mutual solidarity in global justice networks', Environment and Planning A, 39 (11), 2575-92, doi: 10.1068/a38338.

SF Foundation (2015a) '10,000 gardens in Africa', webpage, available at: www.fondazioneslow food.com/en/what-we-do/10-000-gardens-in-africa/.

SF Foundation (2015b) 'Ark of taste', webpage, available at: www.fondazioneslow food.com/en/what-we-do/the-ark-of-taste/.

SF Foundation (2015c) 'Slow Food Presidia', webpage, available at: www.fondazioneslow food.com/en/what-we-do/slow-food-presidia/.

SF Foundation (2015d) 'About the project: history', webpage, available at: www.fondazione slowfood.com/en/what-we-do/the-ark-of-taste/about-the-project/history/.

SF International (2015a) 'About us', webpage, available at: www.slowfood.com/about-us/.

SF International (2015b) 'Terra Madre network', webpage, available at: www.slowfood.com/ our-network/terra-madre-network/.

SF International (2015c) 'Our structure', webpage, available at: www.slowfood.com/aboutus/our-structure/.

SF International (2015d) 'Save biodiversity, save the planet', webpage, available at: www.slowfood.com/expo2015/en/feeding-the-planet/save-biodiversity-save-the-planet/.

SF Netherlands (n.d.) 'Slow Food Nederland', website. available at: www.slowfood.nl/.

SF Netherlands (2014) 'Slow Food', webpage, available at: www.slowfood.nl/index.php?page= Chefintro.

SF NYC (n.d.) 'Snail of approval', webpage, available at: www.slowfoodnyc.org/projects/.

Thelwall, M. (2002) 'Evidence for the existence of geographic trends in university web site interlinking, Journal of Documentation, 58 (5), 563-74, doi: 10.1108/00220410210441586.

Thelwall, M., L. Vaughan and L. Björneborn (2005) 'Webometrics', Annual Review of Information Science and Technology, 39 (1), 81-135, doi: 10.1002/aris.1440390110.

Tilly, C. (2001) 'Mechanisms in political processes', Annual Review of Political Science, 4, 21-41, doi: 10.1146/annurev.polisci.4.1.21.

Varró, K. (2010) 'After resurgent regions, resurgent cities? Contesting state geographies in Hungary and England', published dissertation, Nijmegen, Radboud University Nijmegen, available at: https://goo.gl/kOyKND.

Vasileiadou, E. and P. van den Besselaar (2006) 'Linking shallow, linking deep: how scientific intermediaries use the web for their network of collaborators', Cybermetrics, 10 (1), 1-13, available at: https://pure.tue.nl/ws/files/3878931/391869652795954.pdf. 